\title{
AVALIANDO O IMPACTO DA POLÍTICA BRASILEIRA DE PLANTAS MEDICINAIS E FITOTERÁPICOS NA FORMAÇÃO SUPERIOR DA ÁREA DE SAÚDE
}

\author{
EVALUANDO EL IMPACTO DE LA POLÍTICA BRASILEÑA DE PLANTAS \\ MEDICINALES Y MEDICINA VEGETAL EN LA FORMACIÓN SUPERIOR DEL \\ ÁREA DE SALUD
}

\section{EVALUATING THE IMPACT OF BRAZILIAN POLICY OF MEDICINAL PLANTS AND HERBAL MEDICINES ON THE HIGHER EDUCATION IN HEALTH}

\author{
Kellen Miranda $\mathrm{SÁ}^{1}$ \\ Alberto Sampaio LIMA ${ }^{2}$ \\ Mary Anne Medeiros BANDEIRA ${ }^{3}$ \\ Wagner Bandeira ANDRIOLA ${ }^{4}$ \\ Ronald Targino NOJOSA ${ }^{5}$
}

RESUMO: As plantas podem ser modelos para a síntese de um grande número de fármacos e no caso dos fitoterápicos fazem parte diretamente de sua composição. A Política Nacional de Plantas Medicinais e Fitoterápicos (PNPMF), de 2006, é considerada o marco regulatório da fitoterapia brasileira. O governo brasileiro desenvolveu ações para sua efetivação, entretanto seu avanço foi limitado por fatores tais como o conhecimento insuficiente dos profissionais de saúde sobre fitoterapia. A investigação exploratóriodescritiva objetivou evidenciar as repercussões geradas pela PNPMF na graduação em saúde em um estado do Nordeste brasileiro. A fundamentação baseou-se em revisão de literatura sobre formação superior em saúde no Brasil, diretrizes curriculares nacionais, PNPMF, plantas medicinais em saúde pública e opiniões de grupos-chave da área. Utilizou-se uma abordagem quali-quantitativa, por meio da triangulação entre métodos.

PALAVRAS-CHAVE: Políticas públicas. Plantas medicinais. Práticas pedagógicas. Avaliação da educação superior.

\footnotetext{
${ }^{1}$ Universidade Federal do Ceará (UFC), CE - Brasil. Mestre em Políticas Públicas e Gestão da Educação Superior Fortaleza. ORCID: <http://orcid.org/0000-0001-7490-086X>. E-mail: kellenmiranda@ufc.br

${ }^{2}$ Universidade Federal do Ceará (UFC), Quixadá - CE - Brasil. Professor e Pesquisador nas áreas de Educação e Computação da UFC. Doutor em Engenharia de Teleinformática. ORCID: <https://orcid.org/0000-0003-0696-5148>. E-mail: albertosampaio@ufc.br

3 Universidade Federal do Ceará (UFC), Fortaleza - CE - Brasil. Professora das Disciplinas de Farmacognosia e de Fitoterapia. Doutora em Química. ORCID: <https://orcid.org/0000-0003-4301-4739>. Email: mambandeira@yahoo.com.br

${ }^{4}$ Universidade Federal do Ceará (UFC), Fortaleza - CE - Brasil. Professor da Faculdade de Educação UFC. Bolsista de Produtividade em Pesquisa do CNPq (Nível 1D). ORCID: <https://orcid.org/0000-0001-64590992>.E-mail: w_andriola@ufc.br

${ }^{5}$ Universidade Federal do Ceará (UFC), Fortaleza - CE - Brasil. Professor do Departamento de Estatística e Matemática Aplicada da Universidade Federal do Ceará. Doutor em Estatística pela Universidade de São Paulo. ORCID: <https://orcid.org/0000-0003-3600-572X>.E-mail: rtargino@ufc.br
} 
RESUMEN: Las plantas pueden ser modelos para la síntesis de un gran número de fármacos y en el caso de las medicinas vegetales forman parte directamente de su composición. La Política Nacional de Plantas Medicinales y Medicinas Vegetales (PNPMF), de 2006, es considerada el marco regulatorio de la fitoterapia brasileña. El gobierno brasileño ha desarrollado acciones para su efectividad, sin embargo su avance ha sido limitado por factores tales como el conocimiento insuficiente de los profesionales de salud sobre la medicina vegetal. La investigación exploratorio-descriptiva tuvo el objetivo de evidenciar las repercusiones generadas por la PNPMF en la graduación en salud en un Estado del Nordeste brasileño. La fundamentación se basa en la revisión de literatura respecto a la formación superior en salud en Brasil, directrices curriculares nacionales, PNPMF, plantas medicinales en salud pública y opiniones de grupos clave del área. Se utilizó un enfoque cualitativo cuantitativo, desde la de la triangulación entre métodos.

PALABRAS CLAVE: Políticas públicas. Plantas medicinales. Prácticas pedagógicas. Evaluación de la educación superior.

ABSTRACT: Plants can be models for the synthesis of a large number of drugs and in the case of herbal medicines they are directly part of their composition. The National Policy of Medicinal Plants and Phytotherapics (PNPMF) of 2006 is considered the regulatory framework of Brazilian herbal medicine. The Government developed actions for its implementation, but its progress was limited by factors such as insufficient knowledge of health professionals in phytotherapy. Exploratory-descriptive research aimed to show the repercussions generated by the PNPMF in health graduation in a Brazilian Northeast State. The rationale was based on a review of the literature on higher education in health in Brazil, national curriculum guidelines, PNPMF, medicinal plants in public health and opinions of key groups. A qualitative-quantitative approach was used, through triangulation between methods.

KEYWORDS: Public policies. Medicinal plants. Pedagogical practices. High education evaluation.

\section{Introdução}

O Brasil é um país com dimensões continentais e rica biodiversidade. Segundo Simões et al (2007), a magnitude de sua flora é estimada em torno de 350.000 a 550.000 espécies, o que contribuiu para o uso desses recursos pelas comunidades tradicionais.

A fitoterapia, uso de plantas com atividade medicinal, é uma prática difundida em todo o mundo, em rápida expansão e que tem gerado, segundo Ethur et al (2011), a abertura de mercados nacionais e internacionais. Em termos globais, do total de US\$ 320 bilhões em vendas anuais de produtos farmacêuticos, o mercado de fitoterápicos movimenta cerca de US\$20 bilhões todos os anos, e está em ascensão (VALÉCIO, 2016). 
Realidade bem diversa de décadas atrás, quando a indústria de quimiossíntese farmacêutica internacional dominou a produção de medicamentos sintéticos em larga escala no Brasil, em meados do século XX, ocasionando um decréscimo do uso de plantas medicinais. Segundo Fernandes (2004), a gradual modificação dos currículos básicos de saúde para a alopatia com negligencia da utilização de plantas medicinais restringiu as opções terapêuticas disponíveis.

De acordo com Homar (2005) e Silveira et al (2008), a Conferência Internacional sobre Cuidados Primários de Saúde, realizada em Alma-Ata (1978), possibilitou à Organização Mundial de Saúde (OMS) incentivar países em desenvolvimento a investirem na área das pesquisas com plantas medicinais, pois cerca de $80 \%$ da população mundial depende da medicina tradicional para suas necessidades básicas de saúde e quase $85 \%$ da medicina tradicional envolve o uso de plantas medicinais, seus extratos vegetais e seus princípios ativos (WORLD HEALTH ORGANIZATION, 2011).

Programas governamentais de incentivo à pesquisa com produtos naturais foram então desenvolvidos nas universidades brasileiras, mas não contemplaram o ensino e os currículos das graduações em saúde se mantiveram ligados à alopatia, não havendo o estabelecimento de uma política governamental, mas apenas um incremento das pesquisas de forma isolada, conforme assevera Fernandes (2004).

A partir da Constituição Federal de 1988, a saúde passou a ser um direito do cidadão e um dever do Estado (Brasil, 1988), com a concepção do Sistema Único de Saúde (SUS), através da Lei $\mathrm{n}^{\circ}$ 8.080/90 (Brasil, 1990), com os princípios da universalidade, integralidade assistencial, promoção da saúde e participação da comunidade (HADDAD et al, 2010). Foi priorizada a formação de recursos humanos na área de saúde, continuamente capacitados frente aos constantes avanços das ciências médicas.

Em 2006, a Política Nacional de Plantas Medicinais e Fitoterápicos - PNPMF (BRASIL, 2006), instituída pelo Decreto $\mathrm{N}^{\circ}$ 5.813/06, estabeleceu diretrizes e linhas prioritárias para o desenvolvimento de ações voltadas à garantia do acesso e uso racional das plantas medicinais e fitoterápicos, colocando a capacitação técnico-científica dos profissionais envolvidos em toda a cadeia produtiva das plantas medicinais como estratégia para proporcionar à população o acesso seguro, eficaz e de qualidade a essa terapêutica. Suas diretrizes são amparadas pelo Programa Nacional de Plantas Medicinais e Fitoterápicos (BRASIL, 2009), que enfatiza a capacitação técnico-científica de recursos humanos e preconiza que os centros de formação devem elaborar diretrizes e conteúdos 
curriculares para o Ensino Superior, propiciando a inclusão da formação em Plantas Medicinais/Fitoterapia em todas as áreas de conhecimento relacionadas, visando formar profissionais aptos a proporcionarem à população o acesso às plantas medicinais $\mathrm{e}$ fitoterápicos com segurança, eficácia e qualidade.

A realidade atual demonstra que a fitoterapia ocasiona divergências e não é amplamente utilizada pelos profissionais de saúde. De acordo com Almeida-Filho (2011), os indicadores de recursos humanos de 2009-10 eram de 1,5 milhão de profissionais da saúde registrados em conselhos profissionais, sendo o SUS o principal empregador. Haddad et al (2010) evidenciou a urgente necessidade de harmonizar a relação entre formação profissional e a organização do sistema de saúde brasileiro. Estudos realizados por Figueredo et al (2014) evidenciaram que a implementação da PNPMF pouco avançou em função das dificuldades para seu uso no Sistema de Saúde Único (SUS), devido aos seguintes fatores: pouco conhecimento dos profissionais de saúde sobre Fitoterapia; dúvidas sobre a eficácia e a segurança da terapêutica; dificuldade do acesso à planta medicinal e ao fitoterápico; estruturação dos serviços em moldes que favorecem o uso do medicamento sintético. Barreto (2015) constatou que o ensino de graduação em saúde das Instituições Federais de Ensino Superior (IFES) brasileiras não forma profissionais capacitados ao trabalho com plantas medicinais, ao mesmo tempo em que se verifica a expansão da fitoterapia no país.

Tais constatações reforçam que as universidades brasileiras devam ter um papel importante na PNPMF, visando atender às demandas da sociedade, ao capacitar profissionais de saúde ao mercado na parceria entre Saúde e Educação, com currículos dinâmicos mais voltados para a realidade (GONZE; SILVA, 2011). Faz-se necessário uma visão contemporânea que considere a formação profissional como resultante de um processo que envolva as políticas de ensino, políticas do exercício profissional e as do trabalho em saúde, além de considerar a formação profissional construída em novas bases (FERNANDES, 2013). Para o SUS, Carvalho e Ceccim (2008) salientam competências para a integralidade e enfrentamento das necessidades de saúde da população. Lavor et al (2015) ressaltam que a avaliação dos serviços educacionais de ensino, pesquisa e extensão prestados pelas universidades contribui para a melhoria da qualidade.

A partir da problemática apresentada, a presente pesquisa procurou identificar as repercussões geradas pela PNPMF na formação superior em saúde. Foi realizado um estudo de caso, tendo como escopo o estado brasileiro do Ceará. Partiu-se da hipótese de 
que, durante a graduação, a capacitação da maioria dos profissionais de saúde para o trabalho com plantas medicinais foi deficitária, e que isso pode constituir um problema em saúde pública. Foi realizada investigação nos sites do Ministério da Educação (MEC) e de instituições de ensino superior públicas e privadas que atuam no estado do Ceará, visando a verificação da estrutura/matriz curricular, da presença ou ausência de disciplinas na área de plantas medicinais, além de práticas integrativas/alternativas. Foram coletadas opiniões de especialistas brasileiros, especialistas cearenses, membros de conselhos de classe do Ceará, além de alunos concludentes de cursos de graduação na área de saúde de uma Instituição Federal de Ensino Superior (IFES). O estudo deteve-se às seis principais profissões tradicionalmente e diretamente relacionadas à saúde no estado: enfermagem, farmácia, fisioterapia, medicina, odontologia e nutrição.

\section{Revisão de literatura e trabalhos relacionados}

A avaliação é o processo de determinar - tão sistemática e objetivamente quanto possível - a relevância, efetividade, eficiência e impacto de atividades, em relação a objetivos previamente combinados (BEAGLEHOLE et al, 2010). Conforme asseverado por Alcaraz et al (2012), a experiência de avaliação do ensino deve buscar compreender o processo educativo que ocorre nas salas de aula. Lavor et al (2015) afirma que a avaliação dos serviços educacionais de ensino, pesquisa e extensão prestados pelas universidades, além de ser um tema relevante para a pesquisa, contribui para a melhoria da qualidade desses serviços. Já Fernandes e Flores (2012) constatam que instituições de ensino superior, em nível internacional, têm revelado uma preocupação com as questões da avaliação da qualidade dos docentes e do ensino, ressaltando a importância da utilização de várias fontes de informação e do envolvimento de todos os participantes. Lima e Andriola (2013) enfatizam que a adoção de práticas pedagógicas inovadoras tem ajudado os docentes das instituições de ensino superior, através da melhoria do ensino de graduação, com obtenção de melhores resultados no processo de ensino e aprendizagem.

O Conselho Nacional de Secretários de Saúde (2007) reconhece que o setor da saúde enfrenta crises que podem estar relacionadas ao fato do país ainda não formar profissionais na graduação para o trabalho exclusivo na atenção básica. O SUS tem provocado uma forte pressão política em favor da substituição do padrão reducionista, orientado para a doença, centrado no hospital e orientado para a especialização vigente na 
educação profissional, por outro modelo que seja mais humanista, orientado para a saúde, com foco nos cuidados de saúde primários e socialmente comprometido (ALMEIDAFILHO, 2011).

A Lei das diretrizes e bases da educação, Lei n $9394 / 96$ (Brasil, 1996), concede autonomia didático-científica e adoção de Diretrizes Curriculares para melhor atender ao perfil epidemiológico e social da comunidade, com melhorias para o ensino de graduação, tornando o ensino mais próximo da realidade do SUS. Com o parecer CNE/CES 583/01, o Ministério da Educação e Conselho Nacional de Educação (CNE) (BRASIL, 2001) direcionaram as orientações para as diretrizes curriculares dos cursos de graduação que devem contemplar o perfil do egresso para orientar o currículo para um perfil profissional desejado. Haddad et al (2010) apontam que as Diretrizes Curriculares Nacionais (DCN) dos cursos da saúde necessitam incorporar o arcabouço teórico do SUS. O distanciamento entre mundo acadêmico e o mundo da prestação real dos serviços de saúde vem sendo apontado em todo o mundo como um dos responsáveis pela crise no setor saúde (BRASIL, 2007).

Almeida-Filho (2011) afirma que apesar de conservadoras e elitistas, as universidades não são a principal fonte do problema, porque o sistema de educação da saúde reflete o modelo de prestação de serviços regido por forças de mercado e baseado na tecnologia médica, em vez de fundamentado na solidariedade e em relações sociais mais humanas. Beaglehole et al (2010) afirma que a saúde de uma população é influenciada por uma ampla gama de decisões políticas, não apenas aquelas no campo médico ou da saúde e, portanto, políticas públicas de saúde deveriam fornecer uma estrutura que contemple os determinantes sociais, econômicos e ambientais da saúde.

Duas políticas públicas: a PNPIC (portaria $N^{\circ} 971$, de 03 de maio de 2006) e a PNPMF (Decreto 5.813/06) (BRASIL, 2006), inseriram a temática fitoterapia na educação superior em saúde por meio da articulação com universidades, com incentivo e fomento dos estudos sobre plantas medicinais e fitoterápicos. O Programa Nacional de Plantas Medicinais e Fitoterápicos (PNPMF), criado em 2009, veio reforçar que os centros de formação e capacitação de recursos humanos devem elaborar diretrizes e conteúdos curriculares para o Ensino Superior, visando a inclusão da formação/capacitação em Plantas Medicinais/Fitoterapia em todas as áreas de conhecimento relacionadas.

Pereira et al (2015) ressaltam que o lançamento do PNPMF oficializou a importância dessa terapêutica para o desenvolvimento de fármacos modernos e 
terapeuticamente mais eficazes no Brasil, bem como reconheceu a importância das plantas medicinais para a promoção da saúde. O programa foi consolidado em 2010, com a institucionalização da Farmácia Viva (Portaria N 886) (Brasil, 2010) no âmbito do SUS. Segundo Andrade e Sá (2016), a transição de uma fitoterapia tradicional empírica para uma fitoterapia oficial e mais científica possibilitou aos profissionais de saúde brasileiros as bases para uma prescrição segura, racional e acessível.

Entretanto, Figueredo et al (2014) assevera que apesar de o governo federal brasileiro ter desenvolvido diversas ações, a implementação da PNPM pouco avançou, em função do pouco conhecimento que os profissionais de saúde possuem sobre a Fitoterapia. Barreto (2015) verificou que o quadro nacional da graduação em saúde na área da fitoterapia se constitui um entrave às práticas no país, atentando para o fato de não haver uma uniformidade de conteúdos, metodologias e cargas horárias ideais para esse ensino, como ocorre para outras disciplinas relacionadas aos alopáticos. Gonze e Silva (2011), Figueredo et al (2014) e Barreto (2015) apontam que o ensino da fitoterapia na graduação em saúde ainda é insipiente com a necessidade de mudanças nos currículos.

\section{Método de pesquisa}

Face à natureza da investigação avaliativa, que aborda as opiniões de discentes de saúde, especialistas brasileiros, especialistas cearenses e membros de conselhos de classe, acerca dos impactos da PNPMF no ensino superior em saúde do Ceará, empregou-se na presente pesquisa o método ex-post-facto, conforme apregoa Bisquerra Alzina (2004), também conhecido como método estatístico (GIL, 1999) ou método correlacional. Foi realizada uma triangulação (VERGARA, 2005) entre a literatura que aborda o assunto, a observação das práticas de formação do profissional da área de saúde e a aplicação de questionários com os diversos atores envolvidos no processo para investigar o fenômeno.

O estudo realizado possui cunho quali-quantitativo (YIN, 2001), tendo obedecido aos seguintes passos:

1. Validação da problemática;

2. Revisão de literatura;

3. Planejamento e validação dos instrumentos de pesquisa;

4. Aplicação dos questionários; 
5. Tabulação e análise dos resultados;

6. Publicação dos resultados.

Foi realizada uma análise das Referências Curriculares Nacionais dos cursos de Bacharelados e Licenciatura (RCNCB), e ainda a análise das Matrizes Curriculares de Instituições de Ensino Superior (IES), localizadas no estado do Ceará, em relação ao atendimento à PNPMF e PNPIC, bem como uma análise da Legislação existente dos Conselhos Profissionais de Classe relativa ao exercício profissional em Fitoterapia. Visando complementar a revisão de literatura, a seleção da população foi realizada de acordo com o mostrado no Quadro 1. A amostra (não aleatória) se constituiu de todos os membros das populações-alvo, os quais no período de trinta dias corridos responderam os instrumentos de coleta de dados online (VIEIRA et al, 2010). Foram avaliadas as matrizes curriculares e projetos de cursos de várias IES que ofertam cursos da área de saúde no estado do Ceará. Especificamente no aspecto relacionado à formação discente nesta pesquisa, devido a limitações de tempo, escopo e orçamento, a instituição de ensino superior (IES) avaliada foi a Universidade Federal do Ceará (UFC), pelo fato de ser a IES mais antiga e possuir uma vasta experiência na gestão de cursos da área de saúde no estado. Mesmo com uma recente criação de novos cursos da área de saúde no estado, na última década (atualmente existem 39 IES que ofertam cursos na área), uma grande parcela dos profissionais da área de saúde (enfermagem, farmácia, fisioterapia, medicina, odontologia e nutrição) em atuação no estado do Ceará, inclusive professores das IES que atuam no estado, são egressos dos cursos da UFC. A amostra de alunos entrevistados foi escolhida entre os concludentes do último ano dos cursos, pelo fato dos mesmos possuírem experiência prévia em cursar disciplinas relacionadas à fitoterapia.

Quadro 1: Questionários: Grupos entrevistados, Populações e Amostra da pesquisa

\begin{tabular}{|l|c|c|}
\hline \multicolumn{1}{|c|}{ GRUPOS ENTREVISTADOS } & POPULAÇÃO & AMOSTRA (Respostas) \\
\hline $\begin{array}{l}\text { Especialistas brasileiros em fitoterapia - } \\
\text { questionário com 17 itens destinados a } \\
\text { investigar a percepção sobre o ensino } \\
\text { superior em saúde na área da fitoterapia e } \\
\text { plantas medicinais. }\end{array}$ & 95 & $63(66,31 \%)$ \\
\hline $\begin{array}{l}\text { Especialistas cearenses do Núcleo de } \\
\begin{array}{l}\text { Fitoterapia do Ceará - questionário com 16 } \\
\text { itens destinados a investigar a percepção } \\
\text { sobre o ensino superior em saúde na área } \\
\text { da fitoterapia e plantas medicinais no } \\
\text { Ceará. }\end{array}\end{array}$ & 7 & $7(100 \%)$ \\
\hline
\end{tabular}




\begin{tabular}{|c|c|c|}
\hline $\begin{array}{l}\text { Representantes dos conselhos de classe das } \\
\text { profissões de saúde do Ceará (Farmácia, } \\
\text { Enfermagem, Fisioterapia, Medicina, } \\
\text { Nutrição e Odontologia) - questionário } \\
\text { com } 19 \text { itens destinados a investigar a } \\
\text { percepção sobre o ensino superior em } \\
\text { saúde na área da fitoterapia e plantas } \\
\text { medicinais no Ceará. }\end{array}$ & 6 & $5(83 \%)$ \\
\hline $\begin{array}{l}\text { Alunos concludentes (último ano de } \\
\text { graduação) do Centro de Ciências da } \\
\text { Saúde da UFC - com } 35 \text { itens destinados a } \\
\text { investigar a percepção sobre o ensino } \\
\text { superior em saúde na área da fitoterapia e } \\
\text { plantas medicinais no Ceará. }\end{array}$ & $\begin{array}{l}809 \\
\text { (86 discentes de } \\
\text { enfermagem; } 117 \text { discentes } \\
\text { de farmácia; } 150 \text { discentes } \\
\text { de fisioterapia; } 376 \\
\text { discentes de medicina; } 80 \\
\text { discentes de odontologia). }\end{array}$ & $\begin{array}{l}54(6,7 \%) \\
\text { (16 discentes de enfermagem; } \\
13 \text { discentes de farmácia; } 12 \\
\text { discentes de fisioterapia; } 8 \\
\text { discentes de medicina; } 5 \\
\text { discentes de odontologia). }\end{array}$ \\
\hline
\end{tabular}

Fonte: Elaboração própria

Os questionários semiestruturados (LAKATOS; MARCONI, 2008) utilizaram perguntas com respostas que seguiram a escala de Likert e algumas questões foram formuladas em formato subjetivo. A aplicação dos mesmos foi realizada in loco para o grupo de especialistas cearenses e a distância (web survey) para os demais grupos. Foi utilizada a ferramenta Formulários do Google®. Os dados provenientes receberam tratamento quantitativo estatístico mediante uso do Software gratuito CALC-LibreOffice ${ }^{\circledR}$ versão 5.2.0 para Windows. Os questionários foram validados mediante pré-teste, bem como mediante submissão ao Comitê Permanente de Ética em Pesquisa Envolvendo Seres Humanos da Universidade Federal do Ceará, tendo sido aprovados $\left(\mathrm{N}^{\circ} \mathrm{CAAE}\right.$ : 56349515.7.0000.5054), em cumprimento à Resolução $n^{\circ}$ 466/12, do Conselho Nacional de Saúde. Todos os respondentes assinaram e/ou consentiram o Termo de Consentimento Livre e Esclarecido.

\section{Estudo de caso e análise dos resultados}

O estudo de caso realizado envolveu a avaliação das Referências Curriculares Nacionais dos Cursos de Bacharelados e Licenciatura - RCNCB (Brasil, 2010), que constatou que os cursos de graduação em saúde pesquisados, à exceção do curso de farmácia, não abordam temáticas relacionadas à PNPMF, confirmando os estudos de Barreto (2015) e Haddad et al (2010).

A investigação das Matrizes Curriculares das Instituições de Ensino Superior (IES) foi realizada através do portal do Ministério da Educação e sites das referidas instituições. Evidenciaram-se 39 IES que ofertam cursos de graduação em saúde no estado, com 21 IES 
ofertando disciplinas relacionadas às Práticas Integrativas e Complementares (PI) e/ou Plantas Medicinais e Fitoterápicos (PM) (Figura 1). A PNPIC foi considerada para fins de estudo, pelo fato de englobar Fitoterapia, entre outras áreas.

Verificou-se que a graduação em farmácia atende as diretrizes da PNPMF, fato relacionado ao perfil do egresso descrito nas Diretrizes Curriculares de 2010, onde são exigidas habilidades para o trabalho com insumos, fármacos e medicamentos. Conforme Simões et al (2007), a natureza é considerada fonte para desenvolvimento de medicamentos. O curso de graduação em Odontologia foi o único a não apresentar disciplinas relacionadas à PI e/ou PM.

Figura 1: Frequência de cursos de Graduação em Saúde X cursos de Graduação em Saúde com disciplinas relacionadas às Práticas integrativas e complementares (PI) e/ou Plantas medicinais (PM)

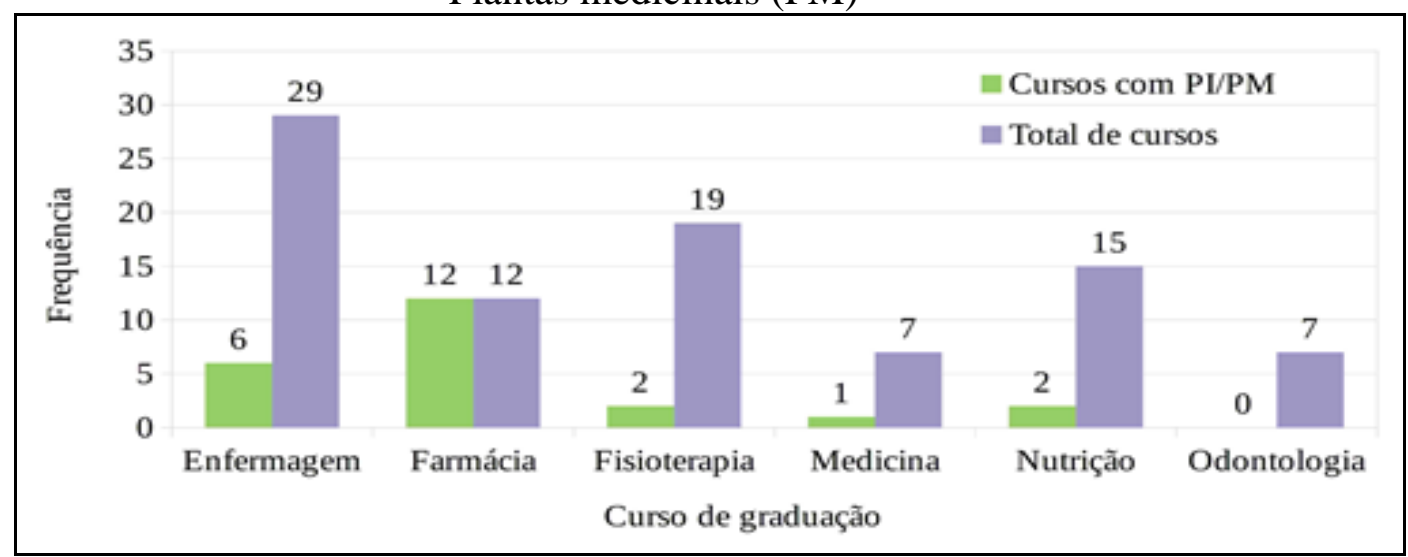

Fonte: Elaboração própria.

Cinco dos Conselhos profissionais de classe estão em acordo com a PNPMF (Tabela 1), possuindo regulamentações específicas sobre o exercício na área. O Conselho de Enfermagem, através da resolução Cofen 0500-2015, revogou a resolução Cofen 197 1997, que tratava da temática relacionada à fitoterapia, e até o fechamento da presente pesquisa não foi identificada alguma resolução que contemplasse diretamente a área.

Tabela 1: Cursos de Graduação de acordo com Apresentação nas Matrizes Curriculares e Legislação profissional da temática: Práticas Integrativas e Complementares, Plantas Medicinais e Fitoterápicos

\begin{tabular}{|c|c|c|c|c|}
\hline CURSOS & $\begin{array}{l}\text { Quanto à } \\
\text { Presença de } \\
\text { disciplinas } \\
\text { Específicas de } \\
\text { Plantas } \\
\text { Medicinais e/ou } \\
\text { Fitoterapia }\end{array}$ & $\begin{array}{l}\text { Quanto à carga } \\
\text { horária ofertada } \\
\text { nas temáticas } \\
\text { Práticas } \\
\text { Integrativas e } \\
\text { Complementares } \\
\text { (PIC) hora/aula }\end{array}$ & $\begin{array}{l}\text { Quanto à carga horária } \\
\text { ofertada na temática } \\
\text { Plantas Medicinais } \\
\text { e/ou Fitoterapia } \\
\text { hora/aula }\end{array}$ & $\begin{array}{l}\text { Quanto à legislação } \\
\text { vigente do Conselho } \\
\text { Federal da Profissão }\end{array}$ \\
\hline
\end{tabular}




\begin{tabular}{l|l|l|c|l}
\hline Enfermagem & - & 9,71 & 1,86 & Sim, indiretamente. \\
\hline Farmácia & $100 \%$ & 5,00 & 173,77 & Sim, diretamente. \\
\hline Fisioterapia & - & 2,10 & 0,42 & Sim, diretamente. \\
\hline Medicina & $14,28 \%$ & - & 2,85 & Sim, diretamente. \\
\hline Nutrição & $13,33 \%$ & - & 6,00 & Sim, diretamente. \\
\hline Odontologia & - & - & - & Sim, diretamente. \\
\hline
\end{tabular}

Fonte: Elaboração própria

Verificou-se que as práticas integrativas em saúde (PIC), embora estejam presentes, ainda se apresentam de forma muito tímida nos currículos de formação no estado do Ceará.

A partir do estudo com especialistas de todas as regiões brasileiras, foi possível compreender diferentes realidades sobre uma mesma temática. A região Sudeste foi a mais representativa em número de especialistas (42\%), fato que pode estar ligado ao desenvolvimento, reforçando a afirmativa do Conselho Nacional de Secretários de Saúde (2007), que indica a concentração de profissionais de saúde nos grandes centros. A região Nordeste teve $20 \%$, seguida pela região Sul com $15 \%$, região Centro-Oeste com $13 \%$ e Região Norte com 10\%. A diversidade da formação acadêmica do grupo (Figura 2) reforçou o caráter multidisciplinar da fitoterapia preconizado pelo PNPMF e confirmado pelos estudos de Andrade (2009). Verificou-se que a classe profissional mais representativa foi a de Farmacêuticos, o que permitiu pressupor que o interesse pela fitoterapia tem possível correlação com a formação acadêmica. Cerca de $80 \%$ dos entrevistados pertencem ao serviço público das áreas de saúde e/ou educação, evidenciando-se um bom nível de formação: 33,33\% de especialistas, 26,98\% de mestres, $20,63 \%$ de doutores e $12,69 \%$ de pós-doutores.

Os resultados obtidos evidenciaram que a graduação em saúde oferecida pelas IES brasileiras é vista como regular, e a formação em plantas medicinais e fitoterápicos como insuficiente (Figuras 3 e 4), sendo as IES estratégicas para essa formação. A inserção de disciplinas na área foi considerada fundamental. A análise qualitativa indicou que o grupo considera importante a obrigatoriedade da oferta de disciplinas (teórico-práticas) na área da PNPMF, com ênfase em uma formação clínica, perpetuando-a para a educação continuada em serviço, inclusive com pós-graduação em fitoterapia (presencial e EAD). O grupo atribuiu que essa carência está diretamente relacionada à falta de interesse pela fitoterapia, conforme foi citado por Rates (2001). O grupo considerou que a extensão universitária deve ser inserida para uma maior racionalidade da terapêutica. Foi ressaltada a necessidade 
de políticas públicas de financiamento para manutenção e ampliação dos serviços de fitoterapia nas instituições de saúde, com apoio dos gestores e investimentos na cadeia produtiva de plantas medicinais que possam atender o aumento da demanda qualitativamente e quantitativamente. Fontenele et al (2013) consideram como principais entraves para uma efetivação da fitoterapia nessas instituições a atenção básica e a sensibilização dos gestores.

Figura 2: Distribuição dos Especialistas Brasileiros segundo a Área de Formação

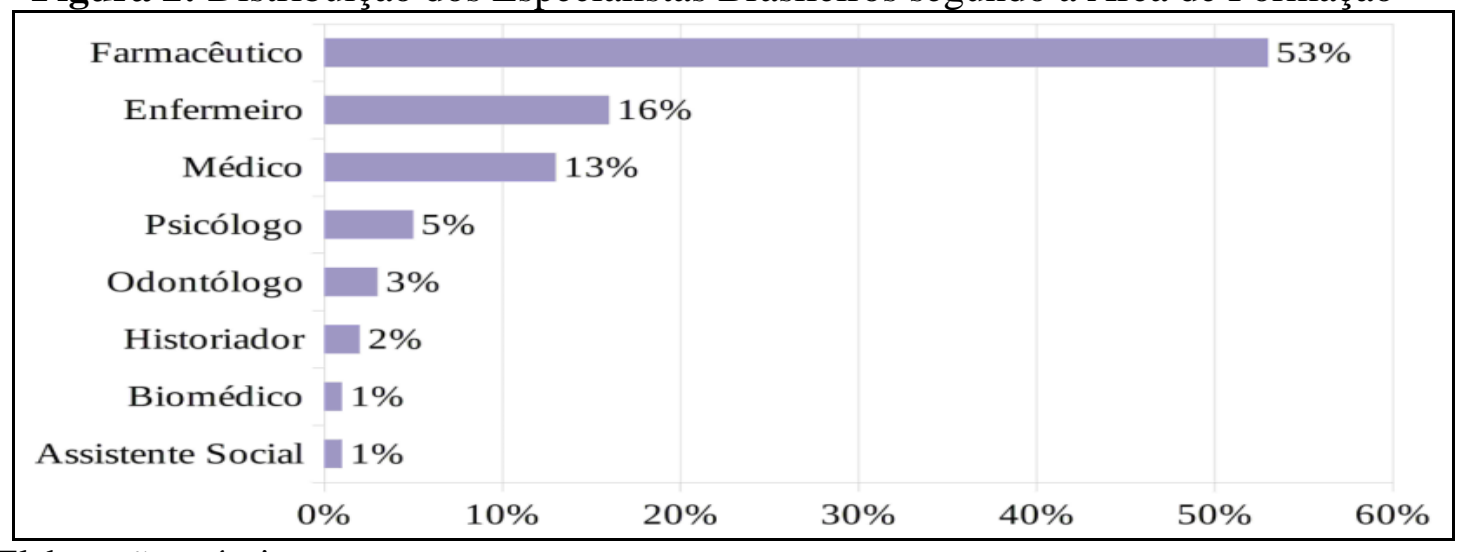

Fonte: Elaboração própria

Durante o estudo, foram entrevistados todos os especialistas em fitoterapia do núcleo de fitoterápicos do estado do Ceará. A entrevista foi realizada in loco. Verificou-se que a equipe de especialistas é formada por 4 engenheiros agrônomos, 2 farmacêuticas e 1 química, vinculados ao governo do estado do Ceará através da secretaria de saúde e/ou secretaria de agricultura. Quanto ao grau de instrução foram identificados 1 mestre, 1 especialista e 5 graduados. A equipe atua na gerência, fiscalização, treinamento/capacitação e implantação de unidades de Farmácias Vivas no estado do Ceará, bem como nos estágios supervisionados na área de fitoterapia de algumas IES, sendo referência na área de fitoterapia em saúde pública.

A formação oferecida pelas IES cearenses para os egressos de saúde foi considerada satisfatória pelos especialistas e a formação em plantas medicinais e fitoterápicos foi considerada regular (Figuras 3 e 4). A inserção de disciplinas de plantas medicinais e fitoterápicos nos cursos de graduação em saúde foi considerada importante por todos os especialistas e a capacitação em serviço considerada necessária para a ampliação da fitoterapia no Brasil e promoção do seu uso racional. A análise das questões subjetivas descreve que os especialistas cearenses acreditam que o pouco interesse dos profissionais de saúde do estado em plantas medicinais ocorre devido à falta de 
conhecimento, mas também aos baixos salários pagos aos profissionais que atuam no setor (referindo-se ao serviço público na atenção primária à saúde). Os especialistas também ressaltaram: falta de aprofundamento das pesquisas com plantas medicinais (ALBUQUERQUE; HANAZAKI, 2006), implementação de políticas públicas (FONTENELE et al, 2013), descrédito da terapêutica, reforçando Veiga-Junior (2008), que constatou que profissionais da área de saúde demonstram grande reticência na indicação das plantas medicinais, especialmente pelo receio dos efeitos adversos. $\mathrm{O}$ grupo considera que para o pleno desenvolvimento do profissional na área são necessárias ações conjuntas entre Ministérios da Educação, Saúde, Agricultura, bem como Prefeituras, estados, entre outros, como citado por Almeida-Filho (2011).

Rates (2001) afirma que deve haver obrigatoriedade da temática nos currículos de graduação das universidades, além da criação de cursos de especialização, cursos de extensão, políticas públicas voltadas para o ensino da fitoterapia, bem como treinamento continuado em serviço. Além disso, a ampliação da pesquisa, ensino e extensão, promoção sistemática de eventos científicos na área, bem como uma maior valorização das práticas integrativas e complementares nos currículos de saúde. Todos os entrevistados avaliaram que a PNPMF não se consolidou para os profissionais de saúde cearenses devido à falta de financiamento para cumprimento de suas diretrizes. Os resultados da pesquisa indicaram que as IES possuem um papel central na formação acadêmica na área de plantas medicinais e fitoterapia no estado, fato que pode ser atribuído em parte ao papel estratégico que a UFC (instituição avaliada) ocupa nas pesquisas com plantas medicinais regionais e à criação do Programa Farmácias Vivas.

Participaram ainda da pesquisa os profissionais de saúde que atuam ou já atuaram nos conselhos de classe de suas profissões. Para esse grupo, a meta foi de cinco respostas, um representante por classe, excluindo-se a profissão de nutrição, devido ao fato de não existir no Ceará o conselho regional para essa categoria. Nenhum conselheiro da área de enfermagem atendeu aos chamados dentro do prazo estabelecido. Foram obtidas respostas de quatro categorias profissionais: Fisioterapia, Farmácia, Medicina e Odontologia. Os resultados indicaram como grau de instrução dos respondentes: 2 especialistas e 2 mestres. Todos os entrevistados trabalham na área pública da saúde, entre gestão, docência e atenção primária. Três dos entrevistados são ligados a algum programa do governo. Os aspectos gerais sobre formação em saúde, atuação profissional e plantas medicinais indicaram que a formação oferecida aos profissionais de saúde pelas universidades para o 
enfrentamento do mercado brasileiro é regular e insuficiente à formação em plantas medicinais. O grupo avaliou também como insuficiente o número de profissionais de saúde que prescrevem e/ou indicam plantas medicinais e fitoterápicos (Figuras 3 e 4). A maioria concorda que as universidades possuem um papel estratégico para a formação de profissionais de saúde aptos ao trabalho com plantas medicinais, considerando fundamental a inserção de disciplinas na graduação. O conhecimento de plantas medicinais e fitoterápicos é visto como imprescindível à ampliação da fitoterapia no Brasil e promoção do seu uso racional.

Entre as principais respostas obtidas nas questões subjetivas, foi identificada uma necessidade de melhoria da qualificação dos profissionais de saúde na área, bem como de ações primárias na esfera municipal, de financiamentos específicos para o setor, inserção da temática em disciplinas da matriz curricular dos cursos de graduação, abertura de cursos de extensão/aprimoramento na área para os profissionais da saúde, melhoria da disponibilidade de fitoterápicos prontos, além de cursos e treinamentos para disponibilizar um maior conhecimento para prescrição e orientação do uso adequado de fitoterápicos. Em relação à resistência de alguns profissionais de saúde em trabalhar com plantas medicinais e fitoterápicos, o principal motivo identificado foi o desconhecimento do assunto. Evidenciou-se que esse desconhecimento é proveniente do despreparo das universidades na abordagem do tema. Ressaltou-se a falta de cultura na classe da saúde em sua utilização e também o desconhecimento das comprovações científicas da eficácia da fitoterapia nas diversas patologias, demonstrando que existe uma necessidade de maior divulgação e realização de estudos englobando a parte clínica da fitoterapia. O grupo vê a inserção de disciplinas de plantas medicinais e medicamentos fitoterápicos nos cursos de graduação de suas áreas como uma alternativa segura para o enfrentamento da falta de medicamentos industrializados, com uma melhor perspectiva na distribuição, dispensa e racionalização, contribuindo para a melhoria da saúde dos usuários. O ensino foi considerado relevante, por propiciar ao profissional o conhecimento necessário para análise crítica frente ao crescimento do mercado dos fitoterápicos e às informações fornecidas pela indústria farmacêutica, o que segundo o grupo tende a maximizar os benefícios de seus produtos em detrimento dos malefícios, contribuindo para uma terapêutica baseada em lucros e não na racionalidade. Foi atribuído papel central às IES na formação acadêmica na área de plantas medicinais e fitoterapia no estado, coincidindo com a opinião dos especialistas cearenses. Tal fato reforça a importância dada pelos especialistas ao papel estratégico da UFC frente 
às pesquisas com plantas medicinais regionais e a criação do Programa Farmácias Vivas no Ceará.

A síntese das opiniões dos grupos de especialistas brasileiros, especialistas cearenses e conselheiros do Ceará, em relação à formação superior em saúde, pode ser visualizada nas Figuras 3 e 4, onde as cores estão associadas à escala de Likert ( 1 a 5 por nível de concordância crescente).

Figura 3: Distribuição dos níveis de concordância dados pelos dos especialistas brasileiros em fitoterapia, especialistas cearenses e conselheiros do Ceará sobre a formação em saúde e plantas medicinais

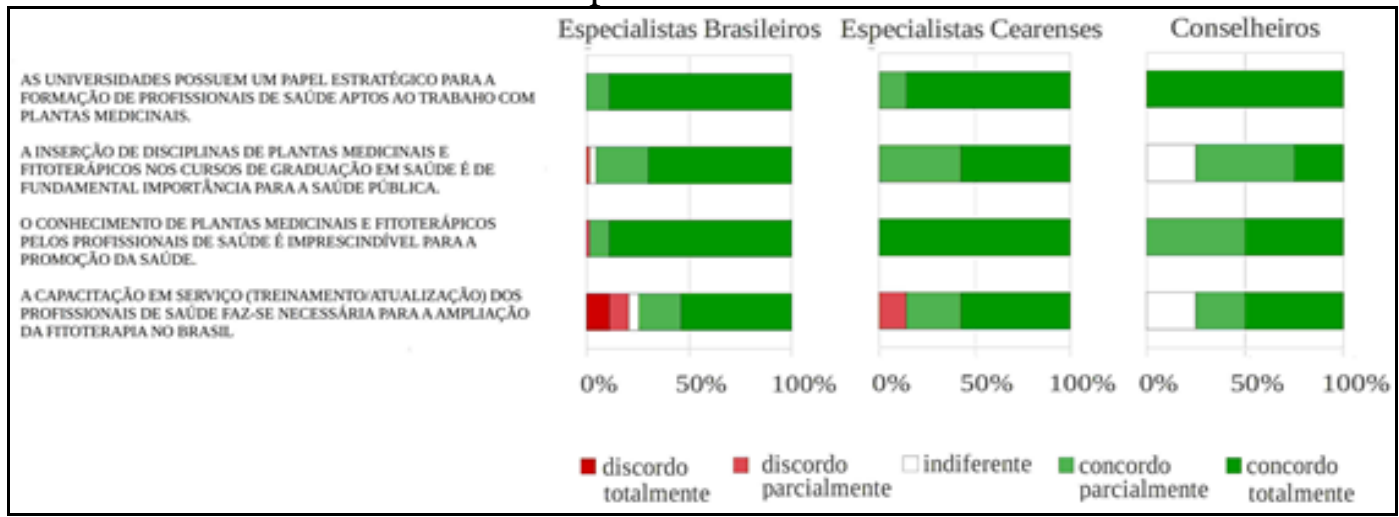

Fonte: Elaboração própria

As opiniões dos três grupos sobre a formação em saúde e em plantas medicinais/fitoterapia oferecida pelas IES é sintetizada no gráfico da Figura 4, em que as cores estão associadas à escala de Likert (muito ruim (1) a muito boa (5)). Em relação à temática plantas medicinais e fitoterápicos apenas 1 dos 63 especialistas brasileiros e 2 dos 7 especialistas cearenses consideram boa a formação. Todos os conselheiros e 87,3\% dos especialistas brasileiros consideram a formação ruim ou muito ruim. Quanto à formação em saúde, quase a metade $(46,0 \%)$ dos especialistas brasileiros consideraram ruim ou muito ruim, enquanto mais da metade $(71,4 \%)$ dos especialistas cearenses a consideraram boa ou muito boa. 
Figura 4: Opinião dos especialistas brasileiros em fitoterapia, especialistas cearenses e conselheiros do Ceará sobre a formação em saúde e em plantas medicinais/fitoterapia oferecida pelas universidades

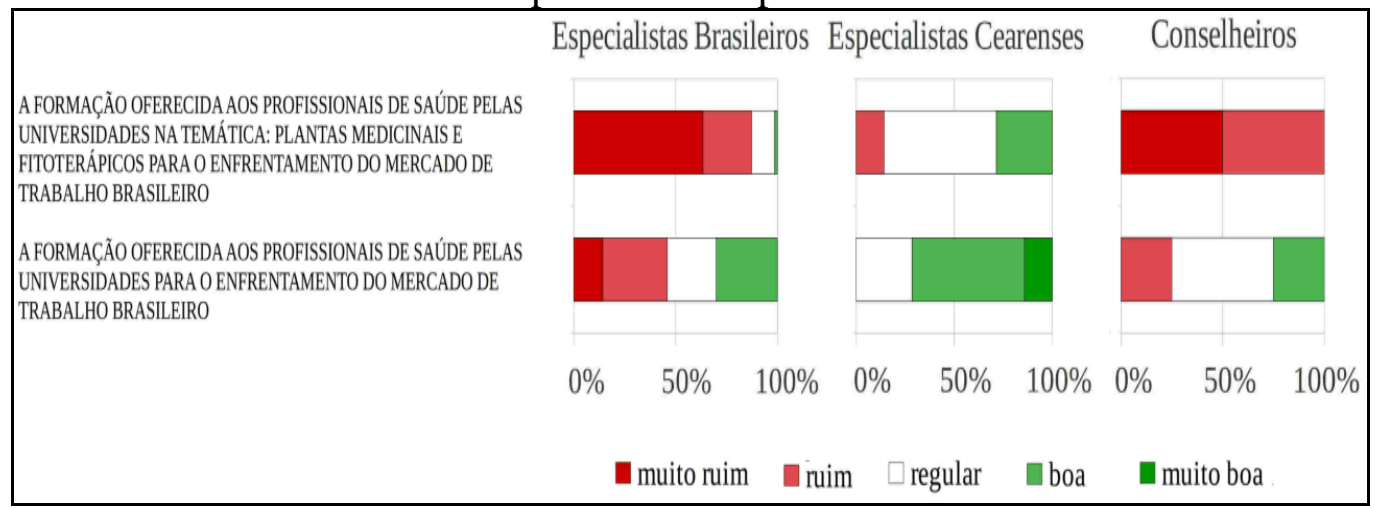

Fonte: Elaboração própria

Já em relação à percepção dos alunos de graduação em ciências da saúde da IES avaliada (uma IFES do Ceará) sobre o ensino das plantas medicinais, foram obtidas respostas de todos os cinco cursos de graduação. Dos 809 questionários enviados, 54 $(6,7 \%)$ foram respondidos, conforme mostrado na Figura 5. A baixa adesão pode ser atribuída a dois possíveis fatores: o primeiro relacionado aos currículos básicos de saúde voltados para a alopatia com negligencia do ensino de plantas medicinais levando a um possível desinteresse, de acordo com Fernandes (2004), o segundo relacionado à escolha da internet para envio dos questionários (web survey), bem como o período de envio dos questionários ter coincidido com o final do semestre letivo. Segundo Cendón et al (2014), as tecnologias ao mesmo tempo que facilitam web surveys têm limitações e uma delas é a tendência para o aumento da taxa de não respondentes. Ressalta-se diversas medidas que foram tomadas ao longo dos 30 dias com o intuito de aumentar a taxa de retorno dos discentes: envio de e-mails, envio de mensagens através das mídias sociais dos cursos e avisos em salas de aula. Vieira et al (2010) consideram que a taxa de retorno dos questionários pode ser considerada satisfatória para pesquisas que utilizam web surveys. Enfermagem e Farmácia foram os cursos com as maiores taxas de retorno, 18,6\% e 11,1\%, respectivamente. Essa ocorrência é um possível indicativo que a inserção de disciplinas de PIC, plantas medicinais e fitoterapia na graduação em saúde sensibiliza o discente na temática, visto que a análise das matrizes curriculares demonstrou serem estes os dois cursos de graduação com maior número de horas-aula. A menor taxa de retorno ocorreu no curso de medicina, $2,1 \%$, embora este tenha sido o curso com maior população (376 discentes). Nesse aspecto, supõem-se demandas formativas alinhadas à alopatia, dado 
reforçado pelos estudos de Peres e Job (2010), em que a medicina da atualidade caminha cada vez mais baseada no intervencionismo exacerbado, e no uso abusivo de medicamentos industrializados, alimentada por intensa ação da indústria farmacêutica. Peres e Job (2010) ressaltam que, devido haver no Brasil restrições à propaganda de medicamentos ao público leigo, o alvo da indústria farmacêutica é o profissional médico. A mesma situação parece estar presente no curso de graduação em odontologia, onde a taxa de retorno ficou em 5,0\%. Nesse sentido, a baixa adesão dos alunos de odontologia à pesquisa na área de plantas medicinais e fitoterapia reflete uma possível formação pautada na alopatia, embasada em Figueiredo (2009) sobre estratégias promocionais da indústria farmacêutica na prescrição odontológica, principalmente por meio dos representantes.

Figura 5: Questionários enviados, respondidos e taxa de retorno (\%) por curso

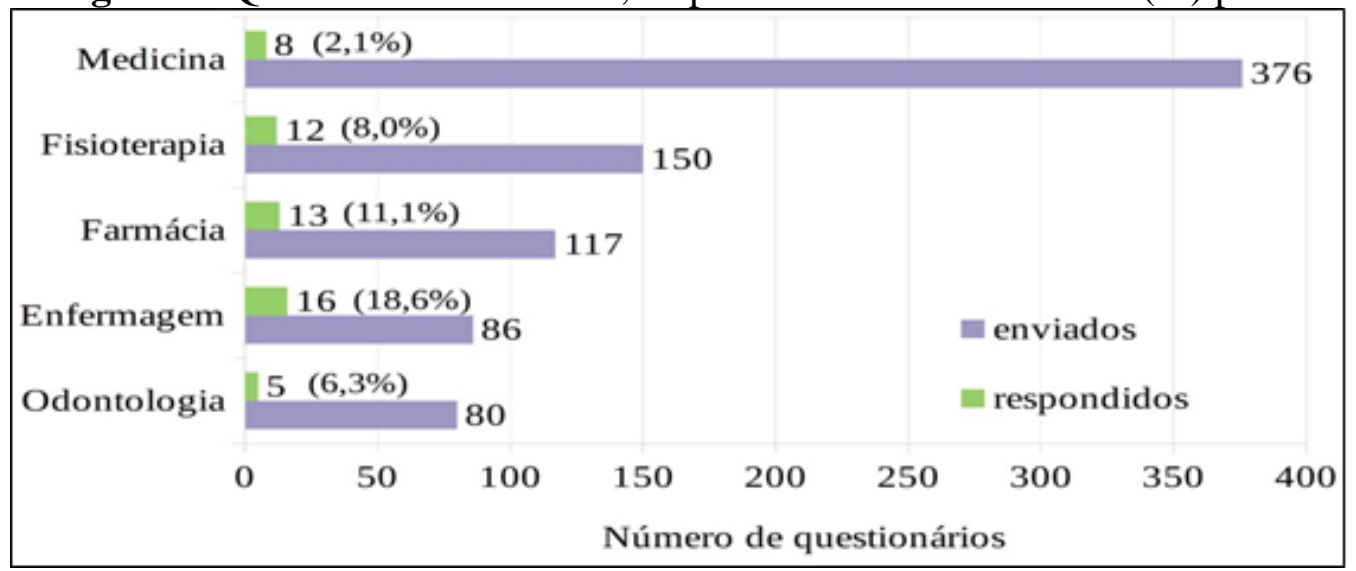

Fonte: Elaboração própria

A análise do perfil dos entrevistados verificou que 76,0\% são mulheres e $24,0 \%$ homens. A idade variou de 18 a 44 anos, sendo a faixa etária predominante de 21 a 23 anos. O perfil socioeconômico demonstrou que a maioria se concentra na faixa de renda média baixa (5 a 10 salários mínimos). Sobre os fatores motivacionais para o estudo em uma Instituição Federal de Ensino Superior foram apontados como decisórios a qualidade do ensino e a gratuidade, o que demonstra que IFES agregam status perante a sociedade estudantil. Os fatores motivadores mais citados para escolha da graduação em saúde foram afinidade e interesse pela área. Quanto à satisfação sobre a formação adquirida na IFES, $63,0 \%$ se declaram parcialmente satisfeitos, porém não se verificou discentes totalmente satisfeitos. Diante da atuação no mercado de trabalho na área de graduação escolhida $51,0 \%$ se declararam aptos parcialmente. Vale salientar que esses discentes já tiveram contato com o mercado de trabalho através dos estágios curriculares da IFES, tendo a 
oportunidade de verificar e testar na prática os conhecimentos aprendidos em sala de aula. A maioria dos discentes percebe os estágios curriculares como algo importante para a prática profissional, pois, quando indagados sobre os estágios curriculares, $89,0 \%$ declararam que os estágios contribuíram parcialmente ou totalmente para a vivência profissional e 90,7\% declararam já ter passado por insegurança diante de uma situação/problema nos estágios supervisionados, cujas causas principais foram atribuídas a inexperiência, falta de preparo e ineficiência do supervisor de campo. Entretanto, diante da mesma situação envolvendo plantas medicinais ou fitoterápicas nos estágios realizados $52,8 \%$ sentiram-se seguros, o que parece indicar que talvez os riscos dessa terapêutica não sejam devidamente conhecidos.

Os estudos de Teixeira e Gomes (2004) reforçam a importância dos estágios, pois afirmam serem as experiências práticas contribuintes para o desenvolvimento do senso de competência em discentes, por integrarem conhecimentos teóricos vistos fora de um contexto aplicado ao longo do curso, adquirindo assim um sentido vivencial.

Quanto à utilização de plantas medicinais 43,4\% declararam usar ou já terem utilizado plantas medicinais e 62,3\% declararam que familiares utilizam ou já utilizaram, demonstrando que a fitoterapia é conhecida no âmbito doméstico. Quanto ao interesse pela área de práticas integrativas em saúde (PIC) que envolvem medicina tradicional chinesa/acupuntura, termalismo, fitoterapia, medicina antroposófica, homeopatia, reiki, entre outras, $66,0 \%$ declararam ter interesse e $81,1 \%$ concordam com a utilização da fitoterapia. Foi possível identificar uma preocupação com a falta de estudos científicos, efeitos adversos, potencial terapêutico como fator limitante para o uso e prescrição. Os discentes reconhecem o baixo custo, a acessibilidade, menores efeitos adversos, tradição de uso, eficácia, nova perspectiva do cuidado holístico como vantagens dos fitoterápicos e $61,5 \%$ dos respondentes confiam nesses medicamentos, pretendendo receitá-los/indicá-los quando forem atuar no mercado de trabalho.

Durante os estágios, 66,0\% dos respondentes indicaram, na comunidade atendida, a prática do uso de plantas medicinais para tratar problemas de saúde, mas afirmaram que seus conhecimentos atuais sobre o assunto são insuficientes, tendo 71,7\% afirmado que o seu curso de graduação não proporciona conhecimentos suficientes sobre plantas medicinais e medicamentos fitoterápicos para enfrentamento do mercado de trabalho (Figura 6). 
Figura 6: Discentes, por curso, quanto à concordância sobre a Graduação Proporcionar conhecimentos suficientes sobre plantas medicinais e fitoterápicos para o enfrentamento do mercado de trabalho

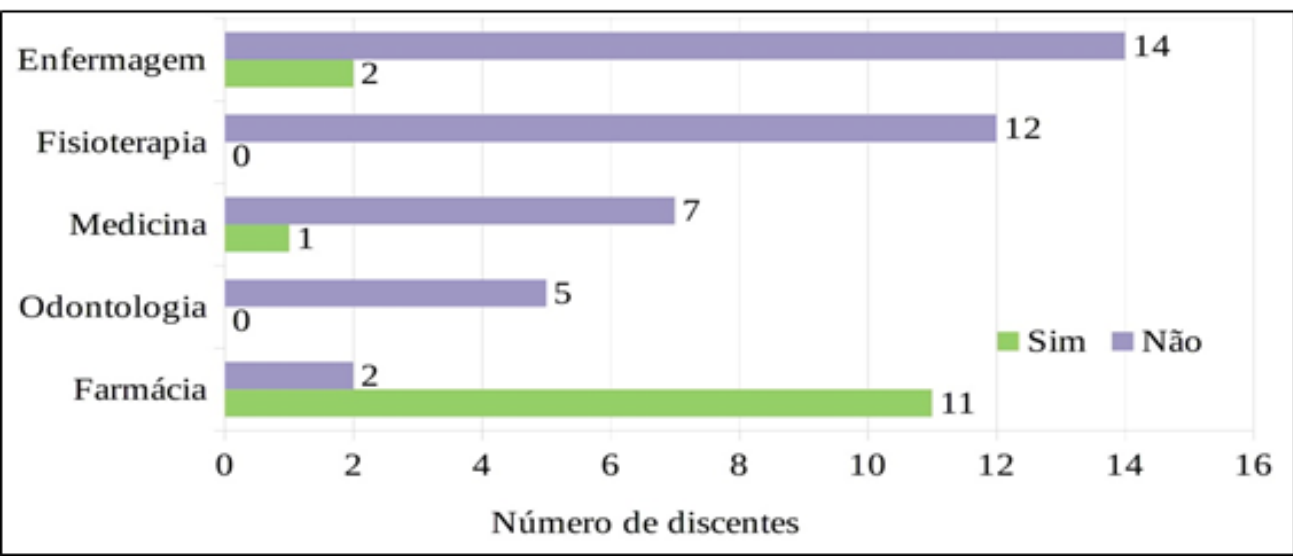

Fonte: Elaboração própria

Cerca de $80 \%$ dos discentes de farmácia acreditam que o conhecimento sobre plantas medicinais e fitoterápicos é suficiente para o enfrentamento do mercado de trabalho. Os outros discentes (Enfermagem, Fisioterapia, Medicina e Odontologia) afirmaram que a graduação não oferece conhecimentos necessários para o enfrentamento do mercado de trabalho, fato que foi verificado nessa pesquisa quando da observação das matrizes curriculares das IES públicas e privadas do Ceará. Tal constatação está presente nos estudos de Barreto (2015), onde em um levantamento realizado apenas com universidades públicas federais brasileiras, observou que somente o curso de Farmácia possuía disciplinas obrigatórias na matriz curricular, dotando o egresso de capacidade para atuar na área. De maneira geral, cerca de $60 \%$ dos discentes concordam com a importância da inserção de uma disciplina de plantas medicinais e fitoterapia na grade curricular, evidenciando interesse por uma formação acadêmica mais próxima da integralidade. Entretanto, somente $38,5 \%$ pretende fazer cursos na área, fato que pode estar relacionado ao mercado de trabalho, conforme citado pelos especialistas cearenses entrevistados nessa pesquisa.

Como apresentado na Figura 7, pode-se observar que a validação científica das plantas medicinais está diretamente relacionada à sua aceitação pelos discentes. Provavelmente, tais opiniões sejam semelhantes para os egressos de cursos da área de saúde. Nesse sentido, cerca de 50\% dos discentes afirmaram que os profissionais de saúde devem agir preventivamente incentivando o uso correto de plantas medicinais pelas comunidades para tratar agravos da atenção primária à saúde (atenção básica). Cerca de 90\% dos respondentes indicaram que o uso de fitoterápicos com finalidade profilática, 
curativa, paliativa ou com fins de diagnóstico é oficialmente reconhecido pela OMS (Organização Mundial de Saúde), o que respalda em parte a terapêutica pelo fato de ser uma organização bastante respeitada na área científica e de saúde coletiva.

Dos discentes entrevistados, foi identificado que cerca de $80 \%$ possuem conhecimento de que a utilização das plantas medicinais é regulamentada no Brasil e concordam que as plantas medicinais, fitoterápicos e serviços relacionados à fitoterapia podem e devem ser usados para ampliar as opções terapêuticas aos usuários do SUS. Entretanto, de uma maneira geral, existe um desconhecimento, indicando a necessidade de uma maior divulgação para que a informação cientificamente validada possa promover uma terapêutica racional. Calixto (2000); Genovés et al (2001); Silva e Ritter (2002); Soares et al (2006) relacionam o aumento do consumo de plantas medicinais "in natura" ou sob a forma de produtos derivados, no Brasil e em outros países à influência da propaganda e divulgação nos meios de comunicação. A indústria farmacêutica ainda exerce um papel importante na escolha da terapêutica, fato que, aliado ao desconhecimento sobre a fitoterapia e engessamento das instituições de ensino superior às demandas mercadológicas, favorece a perpetuação de um modelo biomédico mais caro aos cofres públicos e menos resolutivo, na medida em que se baseia majoritariamente na doença e não na prevenção.

Figura 7: Percentual de discentes em concordância com temas sobre o uso de plantas medicinais e fitoterápicos

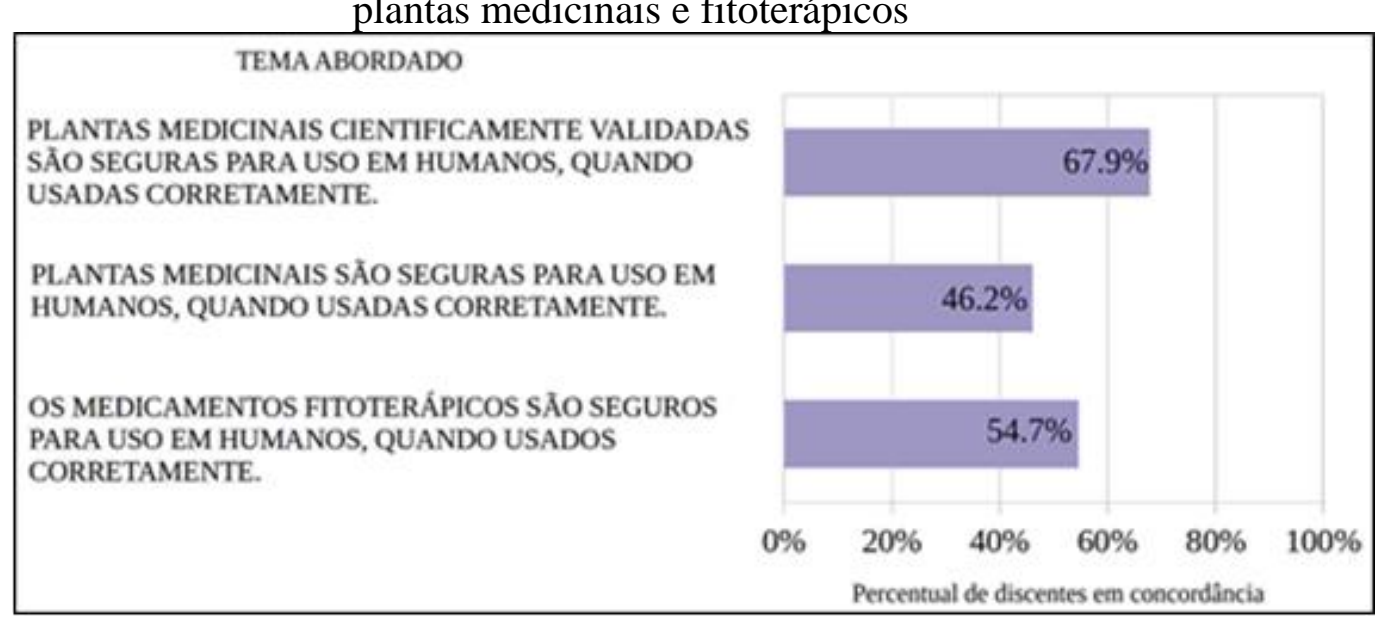

Fonte: Elaboração própria

\section{Considerações finais}


Os resultados obtidos indicaram que existe a necessidade de se trabalhar o ensino da fitoterapia e também das demais práticas integrativas em saúde para proporcionar ao mercado de trabalho brasileiro egressos com um perfil mais próximo aos princípios apregoados pelo SUS. Para isso, sugere-se que o remodelamento das matrizes curriculares dos cursos de saúde seja baseado na proposta de conteúdo sobre plantas medicinais e fitoterápicos para as Instituições de Ensino Superior elaborada por Barreto (2015), a qual tem como base a PNPMF.

Os resultados obtidos na pesquisa indicaram que a PNPMF apresentou poucos impactos nos currículos de graduação em saúde no estado do Ceará, exceção feita à graduação em farmácia. As IES que possuem cursos na área de saúde poderiam ofertar e/ou ampliar a oferta de disciplinas obrigatórias em fitoterapia e demais PIC, bem como buscar uma ampliação dos campos de estágio. Para os estágios curriculares faz-se necessária a intervenção do poder público no sentido de proporcionar políticas públicas de financiamento que permitam a manutenção e perpetuação de profissionais e serviços no SUS, para um atendimento permanente e pleno da população, além da criação de campos de estágio. Para o progresso da PNPMF, deve-se considerar a busca de parcerias a serem firmadas por convênios das universidades com os governos das esferas federal, estadual e municipal, através das secretarias de saúde. Tais parcerias possibilitam as bases de uma fitoterapia oficial e científica. Sugere-se ainda que as unidades assistenciais de fitoterapia do SUS permaneçam ligadas às universidades e demais IES, como forma de retroalimentar o sistema de ensino, pesquisa e extensão, tanto na graduação, pós-graduação e educação em serviço, fornecendo as bases para uma fitoterapia racional e mais científica.

A partir dos resultados obtidos, pode-se ressaltar o potencial das IES no fomento, estruturação e desenvolvimento de pesquisas onde a validação científica das plantas medicinais impacta diretamente na aceitação dessa terapêutica pelos profissionais de saúde (maior segurança e confiabilidade no processo de prescrição e/ou indicação).

Dessa forma, é possível afirmar que a PNPMF ainda depende de fatores intrínsecos e extrínsecos à educação que necessitam de resolução para que se chegue aos resultados esperados. Em relação às Práticas Integrativas em Saúde (PIC) que foram verificadas na pesquisa, foi identificado que embora estejam presentes, ainda se apresentam de forma muito tímida nos currículos dos cursos avaliados. Essa é uma realidade que merece melhor atenção das IES, visto que as PIC são importantes ferramentas que deveriam ser agregadas 
às disciplinas de plantas medicinais e fitoterapia, como um elemento de positividade, incrementando ainda mais a formação do aluno.

Entre as limitações desta pesquisa, no que se refere aos resultados do estudo de caso, especificamente no aspecto da avaliação de discentes, o escopo de uma única IES e a baixa adesão dos alunos da área de saúde pode implicar em alguma dificuldade, no que se refere à generalização de resultados. Apesar das limitações citadas, uma grande parcela dos profissionais da área de saúde que atuam no estado do Ceará são egressos dos cursos da IES avaliada. Considera-se que os resultados gerais obtidos se apresentaram sólidos e promissores, envolveram a análise de vários cursos da área de saúde, ofertados por IES que atuam no estado do Ceará, incluindo algumas IES que atuam em nível nacional. Foi avaliada a percepção de especialistas brasileiros, do estado do Ceará, além de representantes dos conselhos de classe e alunos concludentes de cursos da área. Dessa forma, considera-se que os resultados da presente pesquisa podem contribuir para a melhoria da formação dos profissionais da área de saúde no Brasil.

Como trabalhos futuros, pretende-se repetir o estudo realizado em uma maior quantidade de IES públicas e privadas.

\section{REFERÊNCIAS}

ALBUQUERQUE, U. P.; HANAZAKI, N. As pesquisas etnodirigidas na descoberta de novos fármacos de interesse médico e farmacêutico: fragilidades e pespectivas. Rev Bras Farmacogn, v. 16, Supp 10, p. 678-89, 2006.

ALCARAZ, N.; NAVAS, M. F.; SOLA, M. La voz del alumnado em los procesos de evaluación docente universitaria. Revista Iberoamericana de Evaluación Educativa, v. 5, n. 2, 2012.

ALMEIDA-FILHO, N. Ensino superior e os serviços de saúde no Brasil. The Lancet, maio de 2011. DOI:10.1016/S0140- 6736(11)60326-7. Disponível em:

<http://www.abc.org.br/IMG/pdf/doc-574.pdf>.

ALZINA, R. B. Metodología de la investigación educativa. Madrid: Editorial la Muralla, 2004.

ANDRADE, J. M. T. Antropologia do mundo das plantas medicinais. Rev Habitus, v. 7, n. 1/2, p. 249-263, 2009.

BARRETO, B. B. Fitoterapia como conteúdo nos cursos de graduação da área da saúde: importância para a formação profissional [Tese]. Brasília (DF): Universidade Brasília, 2015. 
BEAGLEHOLE, R.; BONITA, R.; KJELLSTROM, T. Epidemiologia básica. São Paulo: Santos, 2010. Disponível em:

<http://apps.who.int/iris/bitstream/10665/43541/5/9788572888394_por.pdf>. Acesso em: 30 jun. 2016.

BRASIL. Constituição da República Federativa do Brasil. Brasília, DF: Senado Federal, 1988.

BRASIL. Lei ${ }^{\circ}$ 8.080, de 19 de setembro de 1990. Dispõe sobre as condições para a proteção, proteção e recuperação da saúde, a organização e o funcionamento dos serviços correspondentes e dá outras providências. Diário Oficial da União, 1990. Disponível em: <http://www.planalto.gov.br/ccivil_03/leis/18080.htm>. Acesso em: 23 abr. 2016.

BRASIL, Ministério da Saúde (BR). Política nacional de plantas medicinais e fitoterápicos. Brasília (DF): MS, 2006. Disponível em:

<http://bvsms.saude.gov.br/bvs/publicacoes/politica_nacional_fitoterapicos.pdf >. Acesso em: 28 abr. 2016.

BRASIL, Ministério da Saúde (BR). Secretaria de Ciência, Tecnologia e Insumos Estratégicos. Programa Nacional de Plantas Medicinais e Fitoterápicos. Brasília (DF): MS, 2009.

BRASIL. Lei no. 9.394, de 20 de dezembro de 1996. Estabelece as diretrizes e bases da educação nacional. Diário Oficial da União, 23 dez. 1996. Disponível em:

<http://www.planalto.gov.br/ccivil_03/leis/L9394.htm>. Acesso em: 23 abr. 2016.

BRASIL. Lei n ${ }^{\circ}$ 10.172, de 9 de janeiro de 2001. Aprova o Plano Nacional de Educação e dá outras providências. Diário Oficial da União. 10 jan. 2001, Seção 1:1. Disponível em: <http://www.planalto.gov.br/ccivil_03/leis/leis_2001/110172.htm>. Acesso em: 24 abr. 2016.

BRASIL. Ministério da Saúde. Pró-Saúde: Programa Nacional de Reorientação da Formação Profissional em Saúde. Brasília (DF): MS/MEC, 2007. Disponível em: <http://prosaude.org/rel/pro_saude1.pdf>. Acesso em: 28 abr. 2016. 28.

BRASIL. Portaria n⿳0 971, de 03 de maio de 2006. Aprova a Política Nacional de Práticas Integrativas e Complementares (PNPIC) no Sistema único de Saúde Brasileiro. Brasília (DF): MS, 2006. Disponível em:

<http://bvsms.saude.gov.br/bvs/saudelegis/gm/2006/prt0971_03_05_2006.html>. Acesso em: 28 abr. 2016.

BRASIL. Portaria $\mathbf{n}^{\mathbf{0}} \mathbf{8 8 6}$, de 20 de abril de 2010. Institui a Farmácia Viva no âmbito do Sistema Único de Saúde (SUS). 2010. Disponível em:

<http://bvsms.saude.gov.br/bvs/saudelegis/gm/2010/prt0886_20_04_2010.html. Acesso em: 22 ago. 2017.

BRASIL, Referenciais Curriculares Nacionais dos Cursos de Bacharelado e Licenciatura/Secretaria de Educação Superior. Brasília: Ministério da Educação, 
Secretaria de Educação Superior, 2010. 99 p. Disponível em:

$<$ http://www.castelobranco.br/site/arquivos/pdf/Referenciais-Curriculares-Nacionais-v2010-04-29.pdf>. Acesso em: 22 ago. 2017.

CALIXTO, J. B. Efficacy, safety, quality control, marketing and guidelines for herbal medicines (phytotherapeutics agents). Braz J Med Biol Res, v. 33, p. 179-189, 2000.

CARVALHO, Y. M.; CECCIM, R. B. Formação e educação em saúde: aprendizados com a saúde coletiva. In: CAMPOS G. W. S.; MINAYO M. C. S.; AKERMAN M.; DRUMOND JR. M.; CARVALHO, Y. M. (Org.). Tratado de saúde coletiva. 2 ed. São Paulo: Hucitec; Rio de Janeiro: Ed. Fiocruz; 2008. p. 137-70.

CENDÓN, B. V.; RIBEIRO, N. A.; CHAVES, C. J. Pesquisas de survey: análise das reações dos respondentes. Rev Inf \& Soc Est, v. 24, n. 3, p. 29-48, 2014.

ETHUR, L. Z.; JOBIM, J. C.; RITTER, J. G.; OLIVEIRA, G.; TRINDADE, B. S. Comércio formal e perfil de consumidores de plantas medicinais e fitoterápicos no município de Itaqui - RS. Rev. Bras PI Med., v. 13, n. 2, p. 1218, 2011.

FERNANDES, J. D.; REBOUÇAS, L. C. Uma década de diretrizes curriculares nacionais para a graduação em Enfermagem: avanços e desafios. Revista Brasileira de Enfermagem, Brasília, v. 66, n. especial, p. 95-101, set. 2013.

FERNANDES, S.; FLORES, M. A. A docência no contexto da avaliação do desempenho no ensino superior: reflexões no âmbito de um estudo em curso. Revista Iberoamericana de Evaluación Educativa, v. 5, n. 2, p. 82-98, 2012.

FERNANDES, T. M. Plantas medicinais: memória da Ciência no Brasil. Rio de Janeiro: Editora Fiocruz, 2004.

FIGUEREDO, C. A.; GURGEL, I. G. D.; GURGEL JUNIOR, I. G. D. A Política Nacional de Plantas Medicinais e Fitoterápicos: construção, perspectivas e desafios. Physis, v.24, n. 2, p. 381-400, 2014.

FIGUEIREDO, R. R. Uso racional de medicamentos na odontologia: conhecimentos, percepções e práticas. 2009. 106f. Dissertação (Mestrado em Saúde Coletiva) - Instituto de Saúde Coletiva da Universidade Federal da Bahia, Salvador, 2009.

FONTENELE, R. P.; SOUSA, D. M. P. de; CARVALHO, A. L. M.; OLIVEIRA, F. de A. (2013). Fitoterapia na Atenção Básica: olhares dos gestores e profissionais da Estratégia Saúde da Família de Teresina (PI), Brasil. Ciência \& Saúde Coletiva, v. 18, n. 8, p. 23852394, 2013. DOI:10.1590/S1413-81232013000800023.

GIL, A. C. Métodos e técnicas da pesquisa social. São Paulo: Atlas; 1999.

GONZE, G. G.; SILVA, G. A. A integralidade na formação dos profissionais de saúde: tecendo valores. Physis, v. 21, n. 1, p. 129-146, 2011. DOI: 10.1590/S010373312011000100008 . 
HADDAD, A. E.; MORITA, M. C.; PIERANTONI, C. R.; BRENELLI, S. L.;

PASSARELLA, T.; CAMPOS, F. E. Formação de profissionais de saúde no Brasil: uma análise no período de 1991 a 2008. Revista de Saúde Pública, v. 44, n. 3, p. 383-393, 2010. DOI: 10.1590/S0034-89102010005000015.

HOMAR, J. C. Medicinas complementarias o alternativas?: um dilema para el sistema público. Aten Primaria, v. 35, p. 389-391, 2005.

LAKATOS, E. M.; MARCONI, M. A. Técnicas de pesquisa: planejamento e execução de pesquisas, amostragens e técnicas de pesquisa e elaboração, análise e interpretação de dados. 7 ed. São Paulo: Atlas; 2008.

LAVOR, J. F.; ANDRIOLA, W. B.; LIMA, A. S. Avaliando o impacto da qualidade da gestão acadêmica no desempenho dos cursos de graduação: um estudo em Universidade pública Brasileira. Revista Iberoamericana de Evaluación Educativa, v. 8, p. 233-254, 2015.

LIMA, A. S; ANDRIOLA, W. B. Avaliação de Práticas Pedagógicas Inovadoras em Curso de Graduação em Sistemas de Informação. Revista Iberoamericana Sobre Calidad, Eficacia y Cambio em Educación, v. 11, p. 104-121, 2013.

\section{CONSELHO NACIONAL DE SECRETÁRIOS DE SAÚDE. Atenção primária e} promoção da saúde. Brasília (DF): CONASS, 2007. Disponível em:

<http://bvsms.saude.gov.br/bvs/publicacoes/colec_progestores_livro8.pdf >. Acesso em: 6 set. 2016

PEREIRA, J. B. A.; RODRIGUES, M. M.; MORAIS, I. R.; VIEIRA, C. R. S.; SAMPAIO, J. P. M.; MOURA, M. G.; DAMASCENO, M. F. M.; SILVA, J. N.; CALOU, I. B. F.; DEUS, F. A.; PERON, A. P.; ABREU, M. C., MILITÃO, G. C. G.; FERREIRA, P. M. P. O papel terapêutico do Programa Farmácia Viva e das plantas medicinais. Revista Brasileira de Plantas Medicinais, v. 17, n.4, p. 550-561, 2015. DOI: 10.1590/1983084X/14_008.

PERES, G.; JOB, J. R. P. P. Médicos e indústria farmacêutica: percepções éticas de estudantes de medicina. Rev Bras Educ Méd., v. 34, n. 4, p. 515-24, 2010.

RATES, S. M. K. Promoção do uso racional de fitoterápicos: uma abordagem no ensino de Farmacognosia. Rev. Bras. Farmacogn, v. 11, n. 2, p. 57-69, 2001. DOI: 10.1590/S0102695X2001000200001.

SÁ, K. M. A repercussão da política nacional de plantas medicinais e fitoterápicos na formação superior em saúde no estado do Ceará entre 2006 e 2016. 2016. $215 f$. Dissertação (Mestrado em Políticas Públicas e Gestão da Educação Superior) Universidade Federal do Ceará, 2016.

SILVEIRA, P. F. da.; BANDEIRA, M. A. M.; ARRAIS, P. S. D. (2008).

Farmacovigilância e reações adversas às plantas medicinais e fitoterápicos: uma realidade. Revista Brasileira de Farmacognosia, v. 18, n. 4, p. 618-626. DOI: 10.1590/S0102695X2008000400021. 
SOARES, A. K. A.; CARMO, G. C.; QUENTAL, D. P.; NASCIMENTO, D. F.; BEZERRA, F. A. F.; MORAES, M. O.; MORAES, M. E. A. Avaliação da segurança clínica de um fitoterápico contendo Mikania glomerata, Grindelia robusta, Copaifera officinalis, Myroxylon toluifera, Nasturtium officinale, própolis e mel em voluntários saudáveis. Revista Brasileira de Farmacognosia, v. 16, n. 4, p. 447-454, 2006. DOI: 10.1590/S0102-695X2006000400002.

SIMÕES, C. M. O.; SCHENKEL, E. P.; GOSMANN, G. Farmacognosia: da Planta ao medicamento. 6 ed. Porto Alegre/Florianópolis. Ed. Universidade: UFRGS; Ed. UFSC, 2007.

TEIXEIRA, M. A. P.; GOMES, W. B. Estou me formando... e agora?: reflexões e perspectivas de jovens formandos universitários. Rev Bras Orientac Prof., v. 5, n. 1, p. 47-62, 2004.

VALÉCIO, M. Fitoterápicos ganham espaço: guia da farmácia. São Paulo, 2016. Disponível em: <http://www.guiadafarmacia.com.br/suplementos-especiais/fito/fito2016/10793-fitoterapicos-ganham-espaco>. Acesso em: 08 jul. 2016.

VERGARA, S. C. Métodos de pesquisa em administração. 2 ed. São Paulo: Atlas, 2005. 36.

YIN, R. K. Estudo de caso: planejamento e métodos. 2 ed. Porto Alegre: Bookman, 2001.

VEIGA-JUIOR, V. F. Estudo do consumo de plantas medicinais na Região Centro-Norte do Estado do Rio de Janeiro: aceitação pelos profissionais de saúde e modo de uso pela população. Rev Bras Farmacogn, v. 18, n. 2, p. 308-313, 2008.

VIEIRA, H. C.; CASTRO, A. E.; SCHUCH JUNIOR, V. F. O uso de questionários via email em pesquisas acadêmicas sob a ótica dos respondentes. Anais... $13^{\circ}$ Seminários em Administração - SEMEAD, 2010.

WORLD HEALTH ORGANIZATION - WHO. The world medicines situation 2011 Traditional medicines: global situation, issues and challenges. Geneva, 2011.

\section{Como referenciar este artigo}

SÁ, Kellen Miranda de.; LIMA, Alberto Sampaio.; BANDEIRA, Mary Anne Medeiros.; ANDRIOLA, Wagner Bandeira.; NOJOSA, Ronald Targino. Avaliando o impacto da política brasileira de plantas medicinais e fitoterápicos na formação superior da área de saúde. Revista Ibero-Americana de Estudos em Educação, Araraquara, v. 13, n. 03, p. 1106-1131, jul./set., 2018. E-ISSN: 1982-5587. DOI: 10.21723/riaee.v13.n3.2018.11160

Submetido em: 02/03/2018

Aprovado em: 05/05/2018 